\title{
Functional Measurement of Special Education Teachers' and Students' Expectations Toward Job Training for Persons with Intellectual Disability
}

\author{
Guadalupe Elizabeth Morales-Martinez ${ }^{1,{ }^{*}}$, Ernesto Octavio Lopez-Ramirez ${ }^{2}$, \\ Maria Guadalupe Villarreal-Treviño ${ }^{2}$ and Yanko Norberto Mezquita-Hoyos ${ }^{3}$
}

\author{
${ }^{1}$ Research Institute for the University and Education, Universidad Nacional Autonoma de Mexico, Mexico \\ City, Mexico \\ ${ }^{2}$ Department of Psychology, Universidad Autonoma de Nuevo Leon, Monterrey City, Mexico \\ ${ }^{3}$ Department of Psychology, Universidad Autonoma de Yucatán, Mérida City, Mexico
}

\begin{abstract}
Persons with intellectual disability (PWID) have fewer opportunities for enrolment in school programs and post-school employment than do their peers with typical development. Evidence suggests that attitude toward PWID is a main factor in either promoting or limiting better life conditions for this population. In this paper, the goal was to determine the cognitive information integration rules underlying the expectations of 174 special education teachers and students with regard to job training for PWID. In order to accomplish this goal, four factors (Gender, Severity of disability, Type of task, and Emotional traits) were orthogonally combined to implement a cognitive algebra study design. We obtained 48 experimental conditions, with each one presented as a scenario describing a PWID in a work training situation. Participants read these scenarios and were asked to judge the probability of the success of PWID with regard to learning the skills needed to complete the required work. Patterns of response allowed us to identify low, moderate, and high viewpoints with regard to participants' judgments of predicted success. Personal factors (Emotional traits and Severity of disability) and the Type of task factor were considered the most important in influencing the participants' judgment. These factors seemed to be integrated in a complex systematic cognitive pattern. Implications from this type of result with regard to PWID and work training are discussed in this paper.
\end{abstract}

Keywords: Intellectual disability, attitudes, special education teachers, work training, cognitive algebra.

To many adults, the idea of getting a job is a meaningful aspect of our basic life expectancy. Generally speaking, paid employment is not only a well-evaluated social concept associated with wealth, health, economic benefits, and good use of time [1] but it is also associated with psychological dimensions like self-esteem and self-concept [2,3], and strengthens both identity and the sense of self-value $[4,5]$. Moreover, paid employment seems to be associated with life satisfaction [6] and, even more importantly, it imposes a sense of purpose on people's daily experiences [7].

Unfortunately, not all people have the opportunity to gain dignified, paid work. This is frequently the case for people with intellectual disability (PWID), many of whom are underemployed or, as a worst case scenario, jobless [8]. Compared to typical individuals, the PWID population is three to four times less likely to obtain a job [9].

Usually, PWID face tremendous problems regarding job inclusion as well as maintaining employment.

*Address correspondence to this author at the Instituto de Investigaciones Sobre la Universidad y la Educación, UNAM. Circuito Cultural Universitario, Coyoacán 04510, D.F., México; Tel: (55) 5622 6986/95; Fax: (55) 56650123 ;

E-mail: gemoramar@hotmail.com, moramar24@yahoo.com.mx
Academically speaking, not much is known about the nature of factors determining this phenomenon (e.g., moving from school to job inclusion [10], job selection [11], getting and maintaining a job [9], PWID job experiences [12], employers' experiences with hiring PWID).

Overall, previous research addressing this topic has pointed out that the employment-related variables of PWID (e.g., job preferences [13], personal preferences [14], employee demographic profiles [13], motivation and expectations about job attributes [9]), as well as contextual factors (family composition during formative years, school-based staff, early employment experiences, and the community's rehabilitation culture [14]) affect their job opportunities.

In addition, some research suggests that the expectations of PWID with regard to having a job in the future have a profound impact throughout their lives on their rights to access job opportunities, as well as their job conditions. For instance, Doren, Gau, and Lindstrom [15] suggested that parents' expectations about job inclusion significantly predict the capacity of PWID to be independent and that that, in turn, predicts achievement after graduation from school (e.g., obtaining a well-paid job). Complementary research by 
Holwerda, Brouwer, de Boer, Groothoff, and van der Klink [16] found evidence supporting the positive relationship between expectations and the job achievements of PWID. In particular, their results showed that school teachers' expectations for job inclusion were better predictors of the job achievements of PWID than were parents' expectations, and that parents' expectations were, in turn, better predictors of job inclusion than were the expectations of young adult PWID with regard to getting a job.

By considering this academic evidence, the current study explored the cognitive mechanisms underlying beliefs systems, with the aim of determining how the judgments of special education teachers and students with regard to PWID job training relate to job opportunities in Mexico. In particular, the goal is to determine how a variety of factors are evaluated during judgment formation regarding this topic. It is assumed that by comprehending the systematic cognitive functioning underlying judgments about the job opportunities afforded to PWID, it will be possible to specify special education teachers' and students' attitudes and behaviors toward PWID achieving job inclusion.

In order to deal with this academic interest, the Information Integration Theory (IIT) approach is presented here as a useful research tool. The experimental methodology derived from IIT has been widely used to explore human judgment. Specifically, IIT postulates that relevant stimuli are extracted from an environment and psychologically represented through a valuation process with cognitive coefficients. According to this theory, a person is assumed to combine these subjective values by means of a cognitive algebra formula, dominated by addition, multiplication, and averaging, to form a unified implicit response that will produce an explicit response through an action operator.

The IIT approach provides a method to visually identify data patterns from factor interaction graphs to determine universal cognitive principles preceding behavior in several domains (e.g., attitudes toward sexuality [17], love [18], and medical concerns [19]), including the daily life of persons with atypical cognitive development (e.g., moral judgment and Down syndrome [20], love and intellectual disability [21], school inclusion attitudes [22,23], the attitude of PWID toward sexual intercourse $[24,25,26])$.
These cognitive processes regarding valuation, integration, and action can be used to understand and explore cognitive judgments about job training for PWID. Experimentally speaking, the main objective is to observe how much weight the study participants give to each factor, and to determine how these factors are integrated by the participants to produce a prediction about the success of a PWID successfully learning or acquiring a job skill.

\section{METHOD}

The current study applied Anderson's Functional Measurement Theory [27, 28] to the area of special education. This theory empowers cognitive scientists to look for cognitive-psychological laws underlying human judgment. Specifically, it was designed to identify cognitive (algebraic) rules used by people to integrate systematically psychological values derived from different pieces of information. Following this approach, this study considered participants' judgment about four pieces of information (Gender, Severity of disability, Emotional traits, and Type of task) regarding job training for PWID. The goal is to identify participants' judgments of the probability of a PWID to successfully learn a job skill. This academic intention can be formally expressed as the following linear combination of factors:

SELS $=f\left(\mathrm{w}_{\mathrm{G}}\right.$ Gender $* \mathrm{w}_{\mathrm{S}}$ Severity $* \mathrm{w}_{\mathrm{E}}$ Emotionality $*$ $\mathrm{w}_{\mathrm{T}}$ Task)

Where the estimation of successfully learning a skill (SELS) is an information integration cognitive operation $\left({ }^{*}\right)$ combining weighted $(w)$ information factors.

\section{Participants}

A sample of 174 participants was recruited, 59 of whom were special education students (44 women and 15 men). The age range for this sample varied from 18 to 26 years $(M=18, S D=1.2)$. The rest of the sample was made up of 115 special education teachers (105 women and 10 men). Their age range varied from 21 to 58 years old $(M=32, S D=10)$. All participants either studied or worked in the public education system.

\section{Instruments}

We obtained 48 vignettes regarding different training scenarios for PWID, developing a repeated measures factorial design that combines four factors and their levels in an orthogonal way; that is, 2 (Gender: female vs. male) $\times 3$ (Severity of disability: 
low vs. moderate vs. severe) $\times 2$ (Emotional traits: stable vs. volatile) $\times 4$ (Type of task: technological vs. manual vs. service vs. artistic).

Specifically, each vignette described a scenario for a PWID engaged in a training situation. At the end of each scenario, the study participant was asked to rate on a 10 -point scale $(1=$ completely unsuccessful to 10 $=$ completely successful) how probable it was that the scenario actor could learn a job skill. A scenario example can be seen in Appendix 1. Additional demographic information (age, gender, educational level, religious beliefs, and religion) was obtained from the participants through a brief questionnaire.

\section{Procedure}

First, participants were divided into groups. Second, verbal consent was obtained and instructions were provided to all of them. Subsequently, they proceeded with the study, wherein they were required to read each of the 48 scenarios and to rate each of them by using the 10-point ranking scale. Scenarios were randomly presented on printed paper cards. The required time to complete the study varied between 50 to 70 minutes.

\section{RESULTS}

First, a cluster analysis of the raw data (K-means, Euclidean distances) was carried out to see if teachers could be grouped by patterns of response. Subsequently, for each identified group an analysis of variance (ANOVA) was conducted of the participants' responses, according the study design. The objective of this analysis was to explore the cognitive nature typifying judgment within each cluster of participants, as well as to observe the effect of, relevance of, and interactions among the study factors, given the nature of each cluster.

\section{Cluster Analysis}

A cluster analysis of the raw data from the 174 participants was carried out. Considering the patterns of response, three clusters were identified (see Table 1).

These results suggest that each cluster represents a different point of view about job training for PWID. This view varied from a high to a low level of expectation that PWID could learn a job skill. It is also noteworthy that a considerable percentage of participants is grouped inside the moderate expectation of success cluster.

\section{ANOVA Results}

The results of the $2 \times 3 \times 2 \times 4$ (Gender $\times$ Disability severity $\times$ Emotional traits $\times$ Type of task) ANOVA that was conducted for each obtained cluster are shown in Table 2. The significance criterion was set at $p<0.001$. The following three out of the four factors proved to be significant across all of the groups' judgments: Emotional traits, Severity of disability, and Type of task. However, the valuation for each of these factors differed across the clusters (see Figure 1). For example, the low optimistic view cluster gave the highest weight to Severity of disability $\left(\eta_{p}^{2}=0.70\right.$ vs. 0.56 for Emotional traits and 0.12 for Type of task), whereas for the moderate optimistic view cluster, the strongest obtained effect was for the Emotional traits disability factor $\left(\eta_{\mathrm{p}}^{2}=0.72\right.$ vs. 0.58 for Severity of disability and 0.21 for Type of task). Similarly, the strongest main effect for the high optimistic view cluster was obtained for the Emotional traits disability factor $\left(\eta_{p}^{2}=0.74\right.$ vs. 0.67 for Severity of disability and 0.28 for Type of task).

Regarding the information integration cognitive mechanism typifying participants" judgments, the

Table 1: Means of Favorable Expectations (M) and Demographic Characteristics Clusters

\begin{tabular}{|c|c|c|c|c|}
\hline \multicolumn{5}{|c|}{ Distribution of clusters } \\
\hline $\begin{array}{l}\text { Group of the special } \\
\text { school system }\end{array}$ & $\begin{array}{l}\text { Low favorable } \\
\text { expectation } \\
(n=46,26 \%) \\
(M=4.5)\end{array}$ & $\begin{array}{l}\text { Moderate favorable expectation } \\
\qquad(\mathrm{n}=76,44 \%) \\
(\mathrm{M}=6.4)\end{array}$ & $\begin{array}{l}\text { Highly favorable } \\
\text { expectation } \\
\text { (n= 52, 30\%) } \\
(M=8.2)\end{array}$ & Total \\
\hline $\begin{array}{l}\text { Teachers } \\
(\mathrm{M}=6.3)\end{array}$ & $35(30 \%)$ & $47(41 \%)$ & $33(29 \%)$ & 115 \\
\hline $\begin{array}{l}\text { Students } \\
(\mathrm{M}=6.7)\end{array}$ & $11(19 \%)$ & $29(49 \%)$ & $19(32 \%)$ & 59 \\
\hline & & & Total & 174 \\
\hline
\end{tabular}


Table 2: ANOVA Results for the Three Clusters

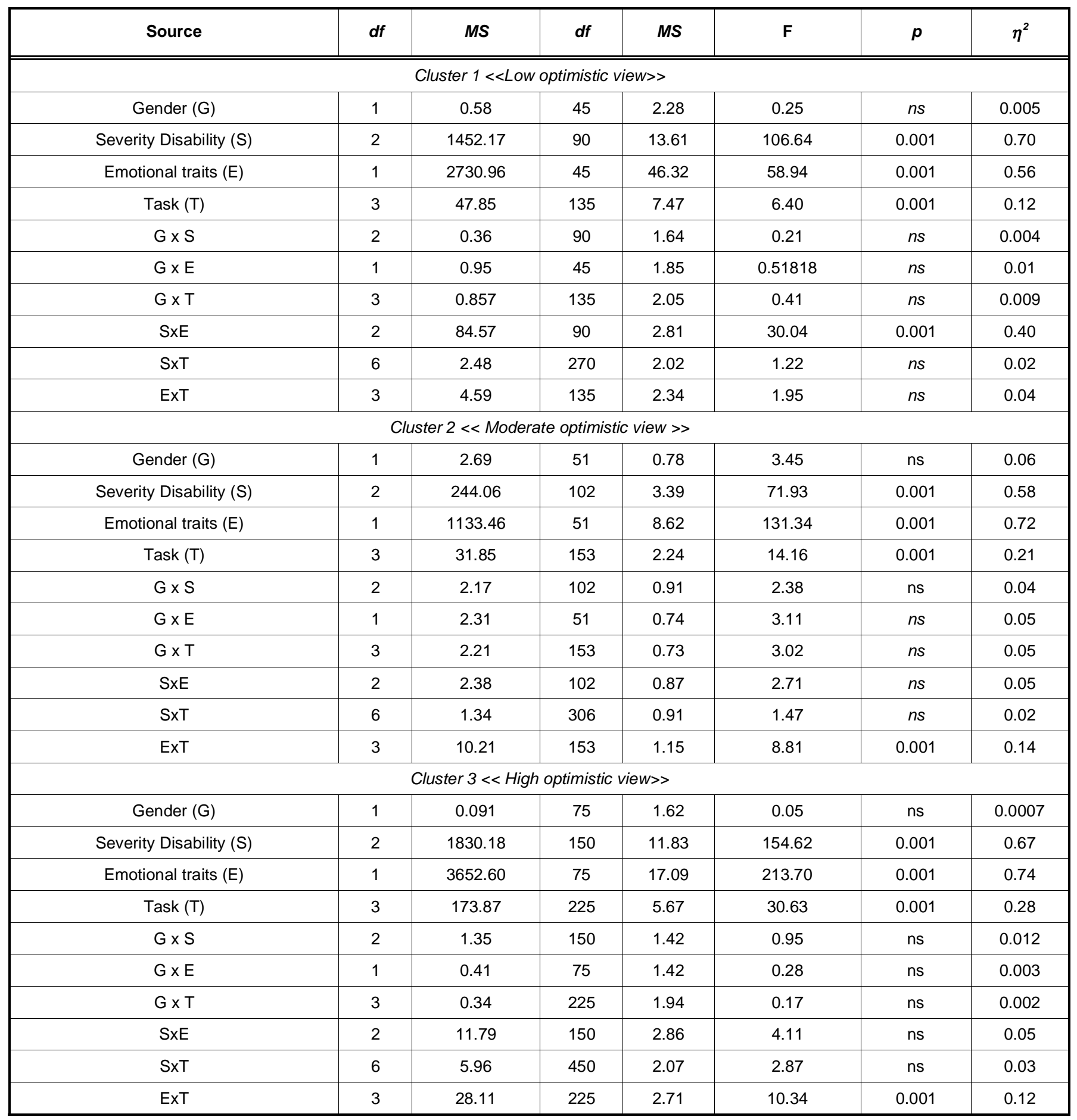

obtained results suggest that participants seemed to use a multiplicative rule to combine study factors. This can be deduced by considering Anderson's Information Integration Theory $[24,25]$ postulation that systematic graphic data patterns of performance reveal algebraic schema integration (additive, multiplicative, or average). For example, the use of multiplicative rules is characterized by a linear fan pattern of response in a factor integration graph, as exemplified by the obtained pattern in this study. See, in particular, the way the experimental factors influenced judgment formation in Figures $\mathbf{1}$ and 2. Two interactions can be identified. First, in Cluster 1, one significant interaction relates to the Severity of disability and Emotional traits factors, 

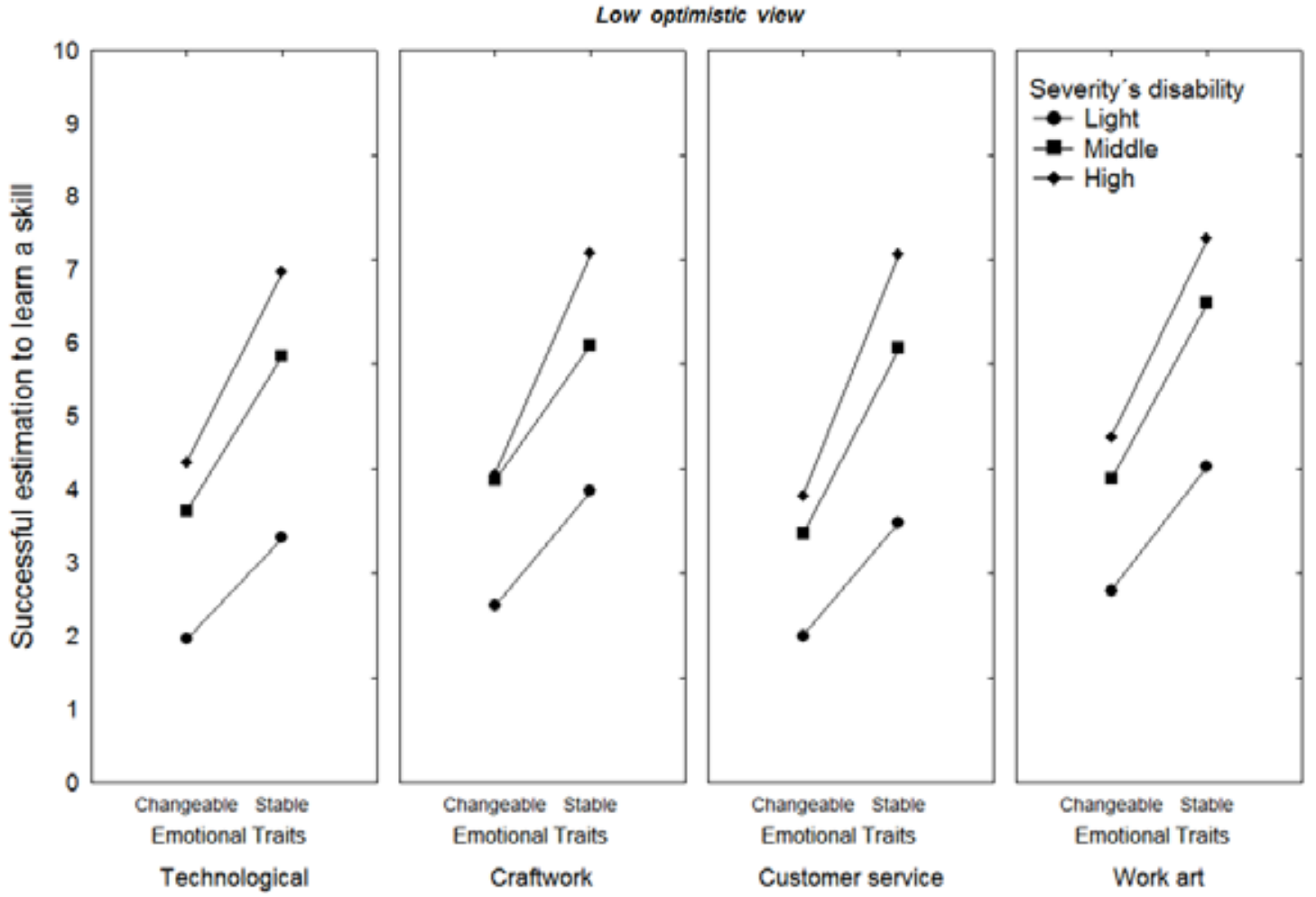

Figure 1: Interaction graph demonstrating the combined effect of Severity of disability, Emotional traits, and Type of task factors on the first cluster of participants' judgments of the success of PWID in learning a job skill.

$F(2,90)=30.04, p<0.001$. The effect of the Severity of disability factor was stronger when the PWID was emotionally stable $(M=6)$ than when the person was volatile $(M=3)$.

Second, in Cluster 2, a significant interaction was found between Emotional traits and Type of task factors, $F(3,153)=8.81, p<0.001$. The Emotional traits factor seemed more relevant when the Type of task to learn was a job related to art (6.9) than when the job was typified by a manual dexterity (6.6), technological (6.3), or customer service (5.8) context. The same result was obtained for Cluster $3, F(3,225)=$ 10.34, $p<0.001$. The Emotional traits factor had a stronger effect when the Type of task was related to art (8.4) than when it was related to a manual dexterity (8.3), technological (8.1), or customer service (7.95) context.

\section{DISCUSSION AND CONCLUSION}

This study explored special education teachers' and students' expectations toward job training of PWID. Overall, the study results showed a low to high positive expectation of success in job training of PWID, depending on the group of participants. Individual factors (e.g., the Emotional traits factor and the cognitive condition) seemed to play an important role in forming participants' expectations. However, it is possible that a higher optimistic expectation could be generated when the judgment is based on attributes relevant to social adaptation, such as emotional traits.

Our results pointed to two ways to evaluate the spectrum of job opportunities for PWID. First, the Cluster 1 participants' judgments appeared to be underlined by a classical point of view, whereby the intellectual condition is a more relevant factor than is adaptive abilities in determining the future of PWID (disease view [29]). On the other hand, participants in Clusters 2 and 3 considered the emotional profile as the aspect of primary importance to learning a job skill. This view is consistent with the idea that social abilities are an important factor to achieve success in social environments, as well as in the workplace. Nevertheless, emotion plays an important role for adaptation to human environments. In particular, no emotional regulation (as is common in many PWID) results in less acceptance from peers, teachers, or other persons. This lack of emotion regulation might reduce the possibility of being included in any environment.

For the three clusters, external factors as regards the nature of the task were considered less important to learning a job skill. However, it is interesting to note 

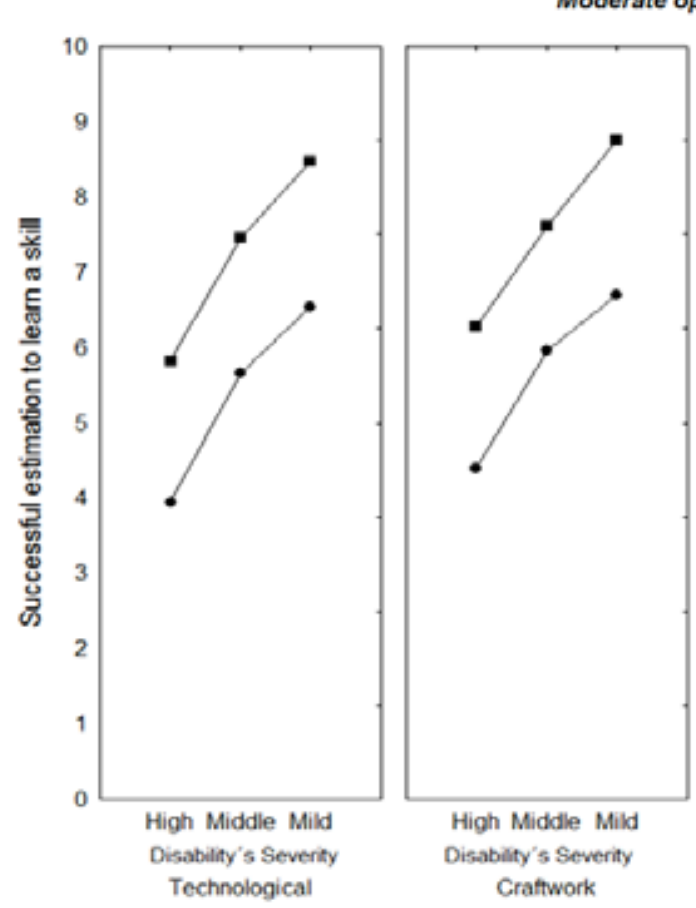

High Middle Mild Disability's Severity Craftwork

High optimistic viow

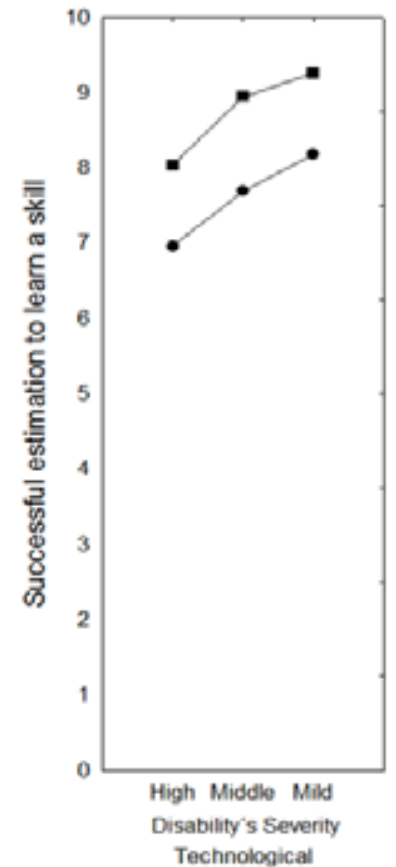

Moderate optimistic view
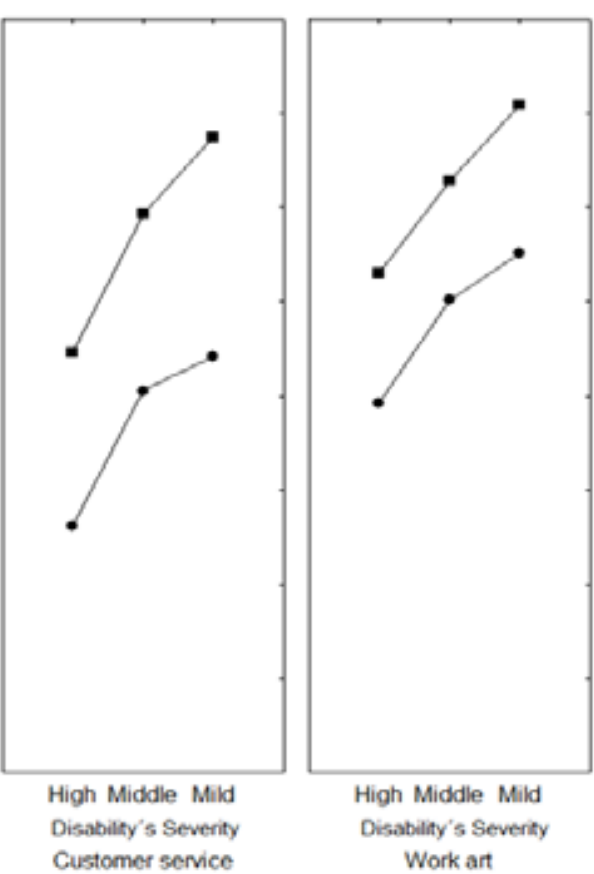

Work art

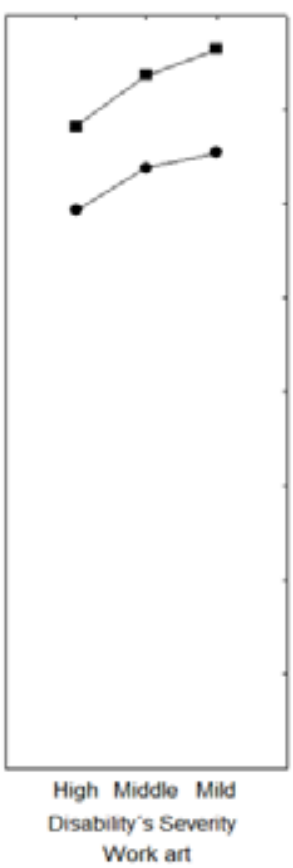

Figure 2: Interaction graph demonstrating the combined effects of Emotional traits, Severity of disability, and Type of task factors on the second cluster (top panels) and third cluster (bottom panels) participants' judgments of the success of PWID in learning a job skill.

that participants attributed to PWID a higher capacity for learning performance activities (e.g., music, painting, handcrafts, computer skills) than social interaction skills (e.g., customer service).

Concerning the judgment formation for probability of the success of PWID in specialized job training, this thinking process seems to be underlined by a complex information integration cognitive mechanism. The study results herein put forward a multiplicative cognitive rule to form expectations of success (see Figures 1 and 2 ).

Overall, results suggest that when PWID are training for a job, teachers and students in the special education system consider that successful job training depends more on individual than on contextual factors. 
It would be very interesting to explore other contextual variables as suggested in previous research (e.g., teaching variables [22]). Furthermore, other research findings have pointed out that cognitive rules to form expectations of success for the job training of PWID could vary depending on the evaluated educational level. For example, unlike the results obtained here, research considering job training of PWID at the elementary school level (preschool, primary school, and high school) has suggested that judgments of success are based on information integration summative cognitive rules in success [22]. This could be the case because job training has a greater temporal proximity to independent living than it does to early education. In early education training, the aim is not just to acquire a job skill but also to display other personal aspects that are essential to tackling more complex situations (e.g., how to adapt to an environment that involves complex human relationships or monitoring regulations).

Implications for the education curriculum to include PWID can be derived from these results regarding social and emotional abilities. This allows them to be prepared not just for intellectual challenges in job environments but also to face challenges in any kind of human interaction.

Open attitudes and favorable expectations about PWIDs' capacities and abilities are essential to promote better opportunities not just in employment but also in all areas of human development. Knowing the lay people's perceptions will empower us to better predict the best environment in which PWID can develop their human potential. This study shows the flexibility and utility of IIT experimental designs to explore perceptions toward PWID. More IIT studies exploring other disabilities and environment factors (e.g., type of disability, social support, training teachers), and other expectation responses (e.g., level of adaptation, ability to perform) are needed to enhance our understanding of the psychological reality of PWID.

\section{APPENDIX 1. EXAMPLE OF EXPERIMENTAL CONDITION}

Ana is a young girl who has a severe intellectual disability. She is a very volatile person. Sometimes she is personable and kind but other times she is impulsive and easily angered. Currently, she wants to learn a trade. She very much likes artistic activities. Because of this, her parents enrolled her in an art workshop so she can learn an artistic skill (e.g., music, painting).
To what extent do you think Ana will be successful in learning this skill?

Completely unsuccessful 0-----0-----0-----0-----0----0-----0-----0------0-----0-----o Completely successful

\section{REFERENCES}

[1] Donellya M, Hillmanb, A, Stancliffeb RJ, Knoxc M, Whitakera L, Parmenterd TR. The role of informal networks in providing effective work opportunities for people with an intellectual disability. Work 2010; 36: 227-237. DOI 10.3233/WOR-20101023

[2] Prins R. Sickness absence and disability: An international perspective. In: Loisel P, Anema JR (eds.) Handbook of work disability: Prevention and management. New York: Springer; 2013; p. 3-14.

http://dx.doi.org/10.1007/978-1-4614-6214-9 1

[3] Robinson J. Access to employment for people with disabilities: findings of a consumer-led project. Disability and Rehabilitation: An International Multidisciplinary Journal 2000; 22(5): 246-253.

\section{http://dx.doi.org/10.1080/096382800296818}

[4] Faunce W. Work, Status and Self Esteem: A theory of Selective Self Investment. Lanham, Maryland: University Press of America Inc.; 2003.

[5] Christiansen $\mathrm{CH}$. Defining lives: Occupation as identity: An essay on competence, coherence, and the creation of meaning, American Journal of Occupational Therapy 1999; 54: 547-558.

http://dx.doi.org/10.5014/ajot.53.6.547

[6] Baldry C, Hallier J. Welcome to the house of fun: Work space and social identity. Economic and Industrial Democracy 2010; 31(1): 150-172.

http://dx.doi.org/10.1177/0143831X09351215

[7] Steger MF., Dik BJ, Duff RD. Measuring meaningful work: The work and meaning inventory (WAMI). Journal of Career Assessment 2012; 00(0): 1-16. Downloaded from jca.sagepub.com at COLORADO STATE UNIV LIBRARIES on February 21, 2012 Downloaded from jca.sagepub.com at COLORADO STATE UNIV LIBRARIES on February 21, 2012.

http://dx.doi.org/10.1177/1069072711436160

[8] Grant J. Paid work - A valued social role that is empowering more people with an intellectual disability and providing employers with dedicated employees! Journal of Intellectual \& Developmental Disability 2008; 33(1): 95-97. http://dx.doi.org/10.1080/13668250701646355

[9] Holwerda A, van der Klink JJL, de Boer MR, Groothoff JW, Brouwer S. Predictors of work participation of young adults with mild intellectual disabilities. Research in Developmental Disabilities 2013; 34: 1982-1990. http://dx.doi.org/10.1016/j.ridd.2013.03.018

[10] Butcher S, Wilton R. Stuck in transition? Exploring the spaces of employment training for youth with intellectual disability. Geoforum 2008; 39: 1079-1092. http://dx.doi.org/10.1016/i.geoforum.2007.11.002

[11] Hall AC, Bose J, Wolfe A, Winsor J. Choosing Employment: Factors That Impact Employment Decisions for Individuals With Intellectual Disability. Intellectual and Developmental Disabilities 2011; 49(4): 285-299. http://dx.doi.org/10.1352/1934-9556-49.4.285

[12] Luftig, RL, Muthert D. Patterns of employment and independent living of adult graduates with learning disabilities and mental retardation of an inclusionary high school vocational program. Research in Developmental Disabilities 2005; 26: 317-325.

http://dx.doi.org/10.1016/j.ridd.2003.08.001 
[13] Rose J, Saunders K, Hensel E, Kroese BS. Factors affecting the likelihood that people with intellectual disabilities will gain employment. Journal of Intellectual Disabilities 2005; 9(1): 923.

http://dx.doi.org/10.1177/1744629505049725

[14] Timmons JC, Hall AC, Bose J, Wolfe A, Winsor J. Choosing Employment: Factors That Impact Employment Decisions for Individuals With Intellectual Disability. Intellectual and Developmental Disabilities; 2011; 49(4): 285-299. http://dx.doi.org/10.1352/1934-9556-49.4.285

[15] Doren B, Gau JM, Lindstrom LE. The relationship between parent expectations and postschool outcomes of adolescents with disabilities. Except Child 2012; 79(1): 7-23.

[16] Holwerda A, Brouwer S, de Boer MR, Groothoff JW, van der Klink JJL. Expectations from Different Perspectives on Future Work Outcome of Young Adults with Intellectual and Developmental Disabilities. J Occup Rehabil 2014. http://dx.doi.org/10.1007/s10926-014-9528-3

[17] Esterle M, Muñoz-Sastre MT, Mullet E. Judging the acceptability of sexual intercourse among persons with learning disabilities: French lay people's viewpoint. Sexuality \& Disability 2008; 26(4): 219-227. http://dx.doi.org/10.1007/s11195-008-9093-9

[18] Falconi A, Mullet E. Cognitive algebra of love through the adult life. The International Journal of Aging \& Human Development 2003; 57(3): 275-290. http://dx.doi.org/10.2190/NPQH-MDLX-F48U-AA35

[19] Hervé C, Mullet E, Sorum PC. Age and medication acceptance. Experimental Againg Research 2004; 30(3): 253-273. http://dx.doi.org/10.1080/03610730490447886

[20] Morales-Martinez GE, Lopez-Ramirez EO, Mullet E (in press). Blame judgments among persons with Down's syndrome. Journal of Intellectual \& Developmental Disability.

[21] Morales GE, Lopez EO, Castro C, Charles DJ, Mezquita YN, Mullet E. Conceptualization of Romantic Love among Adults with Down's Syndrome. Sex and Disability 2014; http://dx.doi.org/10.1007/s11195-014-9368-2
[22] Morales GE, Lopez EO, Villarreal MG, Montalvo ES, Mezquita YN, Castro ME. Cognitive Algebra Underlying Special Education Teachers' and Psychology Students' Attitudes towards School Inclusion of People with Intellectual Disability. Journal of Intellectual Disability - Diagnosis and Treatment 2014; 2(1): 1-9.

[23] Morales GE, Lopez EO, Charles DJ, Castro C, Sanchez MP. Parental and Educators' judgments and attitudes toward life challenges of persons with intellectual disability: functional measurement contributions to special education from a cognitive algebra approach. In Thurgood A, Schuldt K (eds.) Caregivers: challenges, practices and cultural Influences. N.Y. USA: Nova Publisher 2013; pp. 97-117.

[24] Anderson NH. Methods of information integration theory. New York: Academic Press 1982.

[25] Anderson, NH. Unified social cognition. USA: Taylor and Francis Group, L.L. 2008.

[26] Morales GE. Functional measurement to cognitive mechanisms underlying attitudes toward sexuality and intellectual disability: New empirical directions. In Peterson NE, Whitney C (eds.) Sexuality: perspectives, issues and role in society. N.Y. USA: Nova Science Publishers, Inc; 2012; pp. 29-54.

[27] Morales GE, Lopez EO, Mullet E. Acceptability of sexual relationships among people with learning disabilities: family and professional caregivers' views in Mexico. Sexuality and Disability Journal 2011; 29(2): 165-174. http://dx.doi.org/10.1007/s11195-011-9201-0

[28] Morales, MGE, Lopez, REO, Esterle M, Muñoz-Sastre MT, Mullet E. Judging the acceptability of sexual intercourse among people with learning disabilities: A Mexico-France comparison. Sexuality and Disability Journal 2010; 28(2): 81 . 91. http://dx.doi.org/10.1007/s11195-010-9147-7

[29] Santilli S, Nota L, Ginevra MC, Soresi S. Career adaptability, hope and life satisfaction in workers with intellectual disability. Journal of Vocational Behavior 2014; 85(1): 67-74. http://dx.doi.org/10.1016/j.jvb.2014.02.011

\section{DOI: http://dx.doi.org/10.6000/2292-2598.2015.03.01.5}

(C) 2015 Morales-Martinez et al.; Licensee Lifescience Global.

This is an open access article licensed under the terms of the Creative Commons Attribution Non-Commercial License (http://creativecommons.org/licenses/by-nc/3.0/) which permits unrestricted, non-commercial use, distribution and reproduction in any medium, provided the work is properly cited. 